\title{
Is there a difference in outcome between top and side loading instrumentation systems used for the surgical treatment of adolescent idiopathic scoliosis (AIS)
}

\author{
Fallatah Salah* \\ Department of Orthopedics, Umm Al-Qura University, Makkah, Saudi Arabia
}

\begin{abstract}
Different new instrumentation system are available for the surgical treatment of patients with Adolescent Idiopathic Scoliosis (AIS) with more recent emphasis in the three dimensional deformity correction, restoration of normal sagittal alignment and patient based functional out comes. Different surgical approaches and techniques can be utilized for the deformity correction which includes derotation, compression and distraction, in situ bending, and translation. Method: This retrospective study compared two instrumentation technique used to treat AIS, top loading (group I) and side loading (group II) looking at deformity correction, scoliosis research society-30 questionnaire and cost of instrumentation. The hypothesis was that there is no difference in final outcome between the 2 groups. Results: A total of 30 patients (15 in each group) were randomly selected. Mean age was 13.7 years (12.1-17.3), all were female, main curve cobb angle was 630 (41-81) both groups were very similar in their pre operative parameters. Post operative SRS-30 score, percent curve correction, number of instrumented vertebrae were similar between the two groups. The cost of instrumentation was significantly higher in group 2 (7,147 USD for group one and 11,536 USD for group two) which is 38\% higher. There was one minor complication in each group. Conclusion: Top and side loading instrumentation systems utilized in this study gave a very similar post operative results and functional out come with significant cost difference, which might be something to consider when allocating resources and implant purchase and cost for these procedures.
\end{abstract}

\section{Introduction}

Surgical treatment is needed in less than $10 \%$ of the cases of Adolescent Idiopathic Scoliosis (AIS), with different strategies being used for the surgical treatment of AIS. These include: distraction as developed by Harrington [1], which was followed by the development of segmental fixation which allowed segmental compression/distraction $[2,3]$, and later spine de rotation and translation [2-4]. Each one of this technique have its own advantages, disadvantages and some become historic. Recent studies show that the restoration of the sagittal balance (normal thoracic Kyphosis and Lumbar lordosis) is very important in the overall long term benefits from these surgeries and is associated with lower risk of chronic low back pain, disability and final functional outcome with significant development of degenerative disc disease in patients with flat back or thoracic hypokyphosis [5]. Wires, hooks, and screws are used as spine anchors for the deformity correction with recent move toward all screws construct which shows better restoration of sagittal balance, more deformity correction, and reduction of the rib hump through de rotation, avoiding the need for thoracotomy and thoracoplasty, alleviating the need for anterior release in large and stiff curves, all of which at the expense of higher cost and risk of neurological injury [6-8]. The recent advances in surgical instrumentation allowed surgeons better deformity correction especially in complex cases. This is achieved either using a top or side loading spinal instrumentation systems with the former using de rotation technique mainly [9] while the later uses translation mainly [10,11]. In most cases, the use of either a top or side loading spine instrumentation system is related mainly to the surgeon's preference, main method used for deformity correction. The objective of the current retrospective study was to analyze the functional and radiological outcome, as well as the cost of treatment for patient with AIS using two different instrumentation systems (top and side loading).Our Hypothesis was that there is no difference in the final outcome between the 2 systems.

\section{Materials and methods}

Thirty patients were randomly selected from a cohort of patients that underwent posterior scoliosis correction for AIS in the period between 2006-2011 (15 in each group). They were matched for age, curve type and magnitude, Risser stage, and the time of surgery in relation to the study period. The group of patients were selected from the prospective database of all patients underwent surgery for AIS. The randomization was done after creating a table of all patients arranged in alphabetic order then selecting every other 5 patients (total of 15) from each group of the top loading (group 1) and the side loading system (group 2). All patients filled the scoliosis research society-30 questionnaire before and after their surgical treatment and have complete medical records and X-rays. CD Horizon legacy spinal system from medtronic ${ }^{\circledR}$ was used in the top loading group whereas Universal Spinal system (USS)-II spinal system from synthase ${ }^{\circledR}$ and TSRH-SILO spinal system from medtronic ${ }^{\circledR}$ were used in the side loading group. All surgeries were performed by the same surgeon using the same

Correspondence to: Fallatah Salah, Assistant Professor, Department of Orthopedics, Umm Al-Qura University, Makkah, Saudi Arabia, E-mail: salahmf@mac.com

Key words: scoliosis, instrumentation, top loading, side loading

Received: April 24, 2015; Accepted: May 30, 2015; Published: June 03, 2015 

(AIS)

technique for exposure, selection of fusion levels, type of release used, deformity correction method and choice of points and number of spinal anchors. All pedicle screws construct was used in all cases. All patients included in the study have a 2 years minimum follow up. Patients with incomplete medical records or in adequate follow up, or with diagnosis other than AIS were excluded from the original randomization. The decision to use a top loading versus a side loading fixation system was based solely on the available system at the time of surgery and the hospital at which the operation was performed as all surgeries where performed in 4 different hospitals (2 public and 2 private). All patients filled the Scoliosis Research Society questionnaire (SRS-30) before their surgery and at 3, 6, 12, and 24 months after their surgery. Pre and post operative radiographs were reviewed for curve type, fusion levels, number of instrumented vertebrae, percent correction, and sagittal profile as part of the prospective data collection for all patients. SPSS software was used for statistical analysis for determination of means, standard deviation (SDs), as well as percentages. T test was used to study variables with normal distribution and paired t test was used for outcome measures. Qui square and Mann-Whitney tests were used to make comparisons between nonparametric data. Significance was established at $\mathrm{p}=.05$.

\section{Results}

The mean age at the time of presentation was 13.7 years (ranged 12.1-17.3 years), all patients included in this study were females. The cobb angle of the main curve was $63^{\circ}$ (ranged from $41-81^{\circ}$ ). The total number of patients included in this study was 30 divided into 2 equal groups (group 1 was the top loading and group 2 was the side loading). Both groups were similar in their demographic data and pre-operative radiographic parameters (Table 1). There was no significant difference between the two groups with regard to curve magnitude, flexibility, operative time, and number of screws used. The average density of pedicle screws used was similar between the two groups. The average cost of implants was $38 \%$ higher in group two compared to group one $(\mathrm{p}=0.021)$. The average cost of instrumentation in group I was USD $7,147(6,613-8,480)$, and in group II it was USD 11,536 ranging from 9,128 to USD 13,944 , with a significant difference between the two groups. Both groups have similar number of fused levels: 11.5 and 11 in groups 1 and 2, respectively. The comparison of the 2 groups at 2 years follow up show a mean correction of the main curve of $72 \%$ in group 1 and $69 \%$ in group 2, with no statistical difference between the 2 groups. Patients in both groups achieved good correction of the thoracic hump (62.2\% vs. 58.3\% respectively). Patients in both groups presented significant improvement in all domains of the SRS-30. The individual domain scores for pain relief, appearance, activities, mental health, and satisfaction with treatment improved in both groups post operatively with no statistical difference between the 2 group in the overall score (Table 2). One patient in group 1 developed corneal

Table 1. Summary of the results of for the 2 groups.

\begin{tabular}{|l|c|c|c|}
\hline & $\begin{array}{c}\text { Top loading } \\
(\mathbf{1 5} \text { patients) }\end{array}$ & $\begin{array}{c}\text { Side loading } \\
(\mathbf{1 5} \text { patients) }\end{array}$ & P value \\
\hline Age & $13.5(12-17.3)$ & $12.8(11.8-17.1)$ & 0.47 \\
\hline Preoperative major curve cobb $\left(^{\circ}\right)$ & $61.1( \pm 19.1)$ & $60.5( \pm 17.3)$ & 0.52 \\
\hline Postoperative major cobb $\left(^{\circ}\right)$ & $26.7( \pm 21.4)$ & $24.4( \pm 24)$ & 0.5 \\
\hline Preoperative thoracic kyphosis $\left(^{\circ}\right)$ & $24.9( \pm 14.8)$ & $25.4(14.2)$ & 0.52 \\
\hline Postoperative thoracic kyphosis $\left(^{\circ}\right)$ & $33.5( \pm 12.4)$ & $28.8( \pm 12.1)$ & 0.62 \\
\hline Number of fused levels & $11.5(9.3-13.8)$ & $11(8.9-14)$ & 0.66 \\
\hline \% Curve correction & $58.3( \pm 16.5)$ & $54.2( \pm 16.1)$ & 0.09 \\
\hline Implant cost (USD) & $7,147(6,613-8,480)$ & $11,536(9,128-13,944)$ & 0.02 \\
\hline
\end{tabular}

Values represent means and (standard deviation)
Table 2. Two year postoperative Scoliosis Research Society score (SRS-30).

\begin{tabular}{|l|c|c|c|}
\hline & Top loading & Side loading & P value \\
\hline Pain Relief & $4.4( \pm .7)$ & $4.4( \pm .6)$ & 0.3 \\
\hline Appearance & $4.2( \pm .7)$ & $4.1( \pm .7)$ & 0.16 \\
\hline Activity & $4.4( \pm .5)$ & $4.4( \pm .7)$ & 0.6 \\
\hline Mental & $4.2( \pm .6)$ & $4.1( \pm .5)$ & 0.42 \\
\hline Satisfaction & $4.5( \pm .8)$ & $4.4( \pm .1)$ & 0.21 \\
\hline Total & $4.3( \pm .4)$ & $4.3( \pm .5)$ & 0.51 \\
\hline
\end{tabular}

Values respresent means, (standard deviations)

abrasion and 1 patient in group 2 developed early post operative wound drainage (non-infected). There were no neurological complications in the studied population.

\section{Discussion}

There has been a tremendous advances in the surgical treatment of AIS over the past few decades. This was due to the better understanding of the three dimensional deformity of AIS and the development of different types of implants and instrumentation tools that help with better deformity correction and restoration of spinal alignment. In some cases these newer techniques increases the potential risk for complications and cost of surgery. It was suggested that $50 \%$ implant density is sufficient for good deformity correction and satisfactory outcome at 10 years follow up and that a screw at each vertebra bilaterally is not needed in most cases [12,13]. The same was observed when comparing different rod materials used in the deformity correction [14]. Such variety of instrumentation systems and materials give the treating surgeons a wide range of products to choose from, this is even more important with the recent cuts in healthcare budget and the various attempt to decrease the cost of surgical procedures. The surgical care for patients with various spine pathologies is very expensive. This is more true in cases of scoliosis surgery. Several studies showed no difference when using pedicle screws versus hooks in the treatment of some types of AIS and that screws density have no effect on the final post operative SRS score $[15,16]$. Adobor et al. [17] studied the health economic effectiveness of screening of scoliosis and they have estimated the cost of surgery in their study to be 45880 Euro (ranged from 39000-55400 Euro). In another study, Implant cost was fund to be the highest contributor to the overall cost of surgery (29\%) followed by the intensive care and inpatient room stay [18]. Some authors worn against using too much screws in these cases with potential risk of neurological and vascular complications and that in some cases a hybrid construct of screws and hooks give the same results of deformity correction and functional outcome with a lower cost $[19,20]$. In this retrospective study where 2 very similar groups were compared with regard to the top loading and side loading spine instrumentation system, the final post operative deformity correction and SRS-30 scores were very similar. However, the cost of instrumentation was significantly higher in the side loading group when compared with the top loading group with no direct effect on final outcome. This difference in cost is applicable to the instrumentation systems used in this study only, which is one of the limitations of our study, as comparing other top and side loading instrumentation systems may yell different results. Our results may serve as a guide for surgeons, hospitals, and third party payers when considering the overall cost of care for patients with AIS. The ability to use a spine instrumentation system that is safe, provide all maneuvers necessary during surgery for deformity correction and that is less expensive may allow having more funding and resources available to provide care for more patients. Future studies that include more 
patients and other instrumentation systems would definitely be needed to have more power and generalization of the recommendations.

\section{References}

1. Harrington PR (1962) Treatment of scoliosis: Correction and internal fixation by spine instrumentation. J Bone Joint Surg AM 44: 591-610. [Crossref]

2. Luque ER (1982) Segmental spinal instrumentation for correction of scoliosis. Clin Orthop Relat Res 192-198. [Crossref]

3. Cotrel Y, Dubousset J, Guillaumat M (1988) New universal instrumentation in spinal surgery. Clin Orthop Relat Res 227: 10-23. [Crossref]

4. Laxer E (1994) A further development in spinal instrumentation. Technical Commission for Spinal Surgery of the ASIF. Eur Spine J 3: 347-352. [Crossref]

5. Bernstein P, Hentschel S, Platzek I, Hühne S, Ettrich U, et al. (2014) Thoracal fla back is a risk factor for lumbar disc degeneration after scoliosis surgery. Spine $J 14$ : 925-932. [Crossref]

6. Lehman RA Jr, Lenke LG, Keeler KA, Kim YJ, et al. (2008) Operative treatment of adolescent idiopathic scoliosis with posterior pedicle screw-only construct: Minimum three-year follow-up of one hundered fourteen cases. Spine (phila Pa 1976) 33: 1598604. [Crossref]

7. Kim YJ, Lenke LG, Kim J, Bridwell KH, Cho SK, et al. (2006) Comparative analysis of pedicle screw versus hybrid instrumentation in posterior spinal fusion of adolescent idiopathic scoliosis. Spine (Phila Pa 1976) 31: 291-8. [Crossref]

8. Di Silvestre M, Bakaloudis G, Lolli F, Vommaro F, Martikos K, et al. (2008) Posterior fusion only for thoracic adolescent idiopathic scoliosis of more than $80^{\circ}$. Pedicle screws versus hybrid instrumentation. Eur Spine J 17: 1336-49. [Crossref]

9. Lee SM, Suk SI, Chung ER (2004) Direct vertebral rotation: A new technique of threedimensional deformity correction with segmental pedicle screw fixation in adolescent idiopathic scoliosis. Spine (Phila PA 1976) 29: 343-9. [Crossref]

10. Basu S, Rathinavelu S, Baid P (2010) Posterior scoliosis correction for adolescent idiopathic scoliosis using side-opening pedicle screw-rod system utilizing the axia translation technique. Indian J Orthop 44: 42-49. [Crossref]
11. Remes V, Helenius I, Schlenzka D, Yrjonen T, Ylikoski M, et al. (2004) CotrelDubousset (CD) or Universal Spine System (USS) instrumentation in adolescent idiopathic scoliosis (AIS) comparison of midterm clinical, functional, and radiologic outcomes. Spine (Phila Pa 1976) 29: 2024-30. [Crossref]

12. Min K, Sdzuy C, Farshad M (2013) Posterior correction of thoracic adolescent idiopathic scoliosis with pedicle screw instrumentation: results of 48 patients with minimal 10-year follow-up. Eur Spine J 22: 345-54. [Crossref]

13. Bharucha NJ, Lonner BS, Auerbach JD, Kean KE, Trobisch PD (2013) Low-density versus high-density thoracic pedicle screw constructs in adolescent idiopathic scoliosis: do more screws lead to a better outcome? Spine J 13: 375-381. [Crossref]

14. Prince DE, Matsumoto H, Chan CM, Gomez JA, Hyman JE, et al. (2014) The effect of rod diameter on correction of adolescent idiopathic scoliosis at two years follow-up. $J$ Pediatr Orthop 34: 22-28. [Crossref]

15. Quan GM, Gibson MJ (2010) Correction of main thoracic adolescent idiopathic scoliosis using pedicle screw instrumentation: does higher implnat density improve correction? Spine (Phila Pa 1976) 35: 562-7. [Crossref]

16. Kim YJ, Lenke LG, Kim J, Bridwell KH, Cho SK, et al. (2006) Comparative analysis of pedicle screw versus hybrid instrumentation in posterior spinal fusion of adolescent idiopathic scoliosis. Spine (Phila Pa 1976) 31: 291-8. [Crossref]

17. Adobor RD, Joranger P, Steen H, Navrud S, Brox JI (2014) A health economic evaluation of screening and treatment in patients with adolescent idiopathic scoliosis. Scoliosis 9: 21. [Crossref]

18. Kamerlink JR, Quirno M, Auerbach JD, Milby AH, Windsor L, et al. (2010) Hospital cost analysis of adolescent idiopathic scoliosis correction surgery in 125 consecutive cases. J Bone Joint Surg Am 92: 1097-1104. [Crossref]

19. Jaquith BP, Chase A, Flinn P, Sawyer JR, Warner WC, et al. (2012) Screws versus hooks: Implant cost and deformity correction in adolescent idiopathic scoliosis. $J$ Child Orthop 6: 137-43. [Crossref]

20. McCormick J, Aebi M, Toby D, Arlet V (2013) Pedicle screw instrumentation and spinal deformities: have we gone too far? Eur Spine J 22: S216-224. [Crossref]

Copyright: (C2015 Salah F. This is an open-access article distributed under the terms of the Creative Commons Attribution License, which permits unrestricted use, distribution, and reproduction in any medium, provided the original author and source are credited. 